\title{
Cardiovascular Manifestations of Hyperglycemia: A Review Article
}

\author{
Jadelis Giquel $^{1 *}$, Margarita Nieto ${ }^{1}$, Christina Matadial $^{1}$ and Christopher Palermo ${ }^{2}$ \\ ${ }^{1}$ Department of Anesthesiology, Perioperative Medicine and Pain Management University of Miami School of Medicine, USA \\ ${ }^{2}$ Department of Anesthesiology, Miller School of Medicine, University of Miami, USA
}

"Corresponding author: Jadelis Giquel, Assistant Professor, Department of Anesthesiology, Perioperative Medicine and Pain Management University of Miami School of Medicine, Florida, USA, Tel: +1305575315; E-mail: JGiquel@med.miami.edu

Received date: December 3, 2014; Accepted date: December 29, 2014; Published date: December 31, 2014

Copyright: ( 2014 Giquel J, et al. This is an open-access article distributed under the terms of the Creative Commons Attribution License, which permits unrestricted use, distribution, and reproduction in any medium, provided the original author and source are credited.

\begin{abstract}
The overbearing financial burden imposed by the U.S. healthcare system is a complex problem which must be addressed soon. Diabetes, with its multiple cardiovascular sequelae, is currently one of the largest contributors and threatens to worsen as the obesity epidemic blossoms. The implications of atherosclerosis and hypertension related to diabetes may take years to become evident, making the overall disease process a particularly insidious one. Similarities between the biochemical mechanisms of vascular damage in diabetes may someday be the key to preventing its significant morbidity. Until we are able to capitalize on the similarities in the development of complications of hyperglycemia, preventative medicine should be the focus. Lessons should be learned from the widespread success of anti-tobacco legislation and educational programs in decreasing the prevalence of smoking and subsequent pulmonary disease. New York has already passed legislation limiting the size of sugary drinks that can be sold in the city. Efforts should be made to redirect care from the end stages of this particular disease to preventing it in the lower socioeconomic class, where poor diet may be more of an issue.
\end{abstract}

Keywords: National cholesterol education program; Metabolic syndrome; Advanced Glycosolation End Products (AGE); Hyperglycemia; Hypertension; Body mass index; Nephropathy; Retinopathy; Microalbuminuria; Atherosclerosis; Vascular endothelial growth factor; Erectile dysfunction; Gestational diabetes mellitus; Glomerular filtration rate; MetS Criteria

\section{Introduction}

The cardiovascular complications of diabetes are mainly responsible for its significant morbidity and mortality and the abundant cost of diabetes to the U.S. healthcare system. The total economic burden of diabetes in 2012 was $\$ 245$ billion, which was a $41 \%$ increase over 2007 estimates $[1,2]$. The strain imposed by diabetes could be accelerating rapidly as well. In a study by Boyle et al., assuming the increasing incidence of diabetes imposed by the obesity epidemic continues, the prevalence of diabetes could increase from $14 \%$ to a third of the U.S. population by $2050[3,4]$. Globally, the World Health Organization (WHO) estimated there were 217 million people who had diabetes worldwide in 2005. By the year 2030, WHO predicts this number will increase to at least 366 million [5].

Statistics speak loud and clear that there is a strong correlation between cardiovascular disease (CVD) and diabetes [4,5]. Heart disease and stroke are the number one causes of death and disability among people with type 2 diabetes. In fact, at least 65 percent of people with diabetes die from some form of heart disease or stroke [6]. The concept of diabetes as a coronary heart risk equivalent postulates that patients with diabetes who do not yet have CVD are at an equally high cardiovascular risk as non-diabetic patients with CVD [7]. This has led the National Cholesterol Education Program to consider diabetes as a coronary heart disease risk equivalent [8]. Compared to cardiovascular disease in non-diabetics, diabetic patients have a greater overall coronary plaque burden and a higher rate of multi- vessel disease. However, several investigations have found that the cardiovascular risk conferred by diabetes is also strongly associated with female sex, diabetes duration, concomitant risk factors, and the presence of subclinical atherosclerosis [9].

Research has shown a number of diabetes-specific risk factors contributing to the acceleration of atherosclerosis and increased morbidity and mortality of coronary artery disease. This paper reviews the cardiovascular complications of diabetes mellitus and the pathophysiology of its complications including hypertension, retinopathy, end-stage renal disease, neuropathy, peripheral vascular disease, electrolyte imbalances, immune suppression, erectile dysfunction, and complications of pregnancy. These include a discussion of the "metabolic syndrome" that often characterizes diabetes.

\section{Atherosclerosis}

The pathophysiology of the link between diabetes and CVD is complex and multifactorial. Understanding the mechanisms of the disease can help identify and treat CVD in patients with diabetes and vice versa. The acceleration of atherosclerosis in diabetic patients may be explained by hyperglycemia, increased oxidative stress, endothelial dysfunction, increased inflammatory markers, and genetic variables. Hyperglycemia that results from insulin resistance and deficiency increases the rate of advanced glycosolation end product (AGE) formation, decreases nitric oxide (NO) levels, and activates protein kinase $\mathrm{C}$ (PKC) resulting in apoptosis, decreased intrinsic endothelial vasodilation, and impaired cellular function. All these mechanisms have the common effect of an increased oxidative stress state (Table 1) [10].

Hyperglycemia is the major causal factor in the development of endothelial dysfunction in diabetes mellitus. Endothelial vasodilation and vascular reactivity are known to be impaired early in the disease 
Page 2 of 5

process. Several studies have shown that endothelial cell dysfunction is characterized by impaired NO-mediated vasodilation and increased synthesis of vasoconstrictor prostanoids and endothelin [11-14].

Diabetes also disrupts the coagulation cascade leading to a prothrombotic state $[15,16]$. Platelet function is impaired and expression of both glycoprotein Ib and IIb/IIIa is increased [17]. In diabetes, prothrombotic factors such as Factor VII, thrombin, and tissue factor are all increased. In turn, the levels of endogenous anticoagulants thrombomodulin and protein $C$ are decreased [18]. The overall result of the above changes is an increased tendency to clot formation and resistance to fibrinolysis.

The truly concerning aspect of the atherosclerotic changes associated with hyperglycemia is their surreptitious nature. Patients may have advanced vascular endothelial damage for year but only present once a plaque has acutely ruptured. In a Chinese study of 5309 patients, impaired fasting glucose alone was associated with stenosis of cerebral and carotid vasculature as measured by Doppler studies [19]. It has been shown that there is a significantly greater amount of cognitive decline over 20 years in a study of middle-aged adults. A significant difference was noted among prediabetics as well [20]. BMI and diabetes were independent predictors of the development of heart failure at 5 year follow up in 6814 patients who had no clinical heart disease at baseline [21]

\section{Hypertension}

Hypertension is a well-established CVD major risk factor. Hypertension is approximately twice as common in patients with diabetes compared with patients without the disease, adding significantly to its overall morbidity and mortality [22]. Factors that contribute to hypertension in these patients include obesity, insulin resistance, hyperinsulinemia, and renal disease. The heightened sympathetic tone during hyperinsulinemia can lead to sodium retention and subsequent fluid expansion, raising BP. Angiotensin II inhibits insulin's effects in vascular tissue by decreasing nitric oxide production, increasing myosin light chain activation, increasing intracellular calcium, and decreasing uptake of magnesium. All of these mechanisms independently result in vasoconstriction. The mechanism by which type 1 and type 2 diabetics develop hypertension is different with the former being secondary to nephropathy (Table 1) [23].

Also, patients with pre-existing hypertension have an increased risk of developing Type 2 diabetes due to vascular hypertrophy, increased fat deposition in skeletal muscle, and decreased receptor responsiveness. This leads to decreased delivery of insulin and glucose to the muscle and insulin resistance [24]. In addition to the development of diabetic nephropathy, at least three other risk factors have been proposed to contribute to hypertension in diabetes: hyperinsulinemia, extracellular fluid volume expansion, and increased arterial stiffness [25-27].

In patients with type 1 diabetes mellitus the development of hypertension starts years after diagnosis and is clearly related to microalbuminuria. Blood pressure (BP) tends to increase three years after the onset of microalbuminuria [28]. Hypertension exacerbates diabetic nephropathy and contributes to a vicious cycle of microvascular derangement [29]. Diabetics with hypertension require tighter control of blood pressure as indicated by the UK Prospective Diabetes Study Group in which patients with a BP goal of $<150 / 85$ had a $24 \%$ reduction in diabetes related end points including myocardial infarction, stroke, and retinopathy [30].

\begin{tabular}{|c|c|c|}
\hline Cardiovascular Complication & Mechanism & Implication \\
\hline Atherosclerosis & AGE formation, Decreased NO levels, PKC Activation & $\begin{array}{l}\text { Vessel Constriction, Poor Perfusion, Plaque } \\
\text { Development/Rupture }\end{array}$ \\
\hline Hypertension & $\begin{array}{l}\text { Increased metabolic stress/Sympathetic Activation, Sodium } \\
\text { retention/Fluid Expansion }\end{array}$ & $\begin{array}{l}\text { End Organ Damage (Heart, Kidney, Eye), Vascular } \\
\text { endothelial dysruption }\end{array}$ \\
\hline Retinopathy & $\begin{array}{l}\text { Decreased vascularity/Poor oxygen delivery, Increased } \\
\text { Vascular Permeability/ Macular Edema }\end{array}$ & Blindness \\
\hline End-Stage Renal Disease & Decreased GFR, Albuminuria & Dialysis \\
\hline Neuropathy & $\begin{array}{l}\text { Increased sorbitol and fructose formatione, AGE formation, } \\
\text { PKC Activation }\end{array}$ & $\begin{array}{l}\text { Foot ulcers, Delayed gastric emptying, Silent myocardial } \\
\text { infarction }\end{array}$ \\
\hline Erectile Dysfunction & Decreased NO formation, Increased VEGF and ET-1 & Sexual dysfunction, Psychosocial implications \\
\hline Complications of Pregnancy & Interference in insulin receptor signaling & Infant/Maternal mortality \\
\hline
\end{tabular}

Table 1: Cardiovascular Complications of Diabetes.

\section{Retinopathy}

Diabetic retinopathy is the leading cause of blindness in working age adults. The retinal anatomy makes it susceptible to the metabolic derangements caused by diabetes. The inner retina has a decreased vascularity and the cells have few mitochondria to allow light to pass through. As a result, the inner retina has a low oxygen tension even though it has a high demand for it. Decreased visual acuity can also be attributed to increased microvascular permeability and macular edema
[31]. Diabetes increases the release of the cytokines which make vessels more permeable such as vascular endothelial growth factor (VEGF) [32]. Recent research in knockout mice by Huang et al. has demonstrated that lack of the gene promoting placental growth factor (PIGF) decreases VEGF and prevents diabetic retinopathy [33]. 


\section{End-stage renal disease}

Diabetes remains the most common etiology of chronic renal disease, which affects $11 \%$ of the U.S. population. Renal disease alone can increase cardiovascular risk and the issue is only compounded by coexisting diabetes. Diabetics with microalbuminuria, a complication of renal disease, have twice the risk of cardiovascular disease [34]. About $40 \%$ of diabetics will gone on the develop kidney disease and diabetes accounts for $50 \%$ of all new cases of end stage renal disease (ESRD). Patients with ESRD have significantly increased mortality and the costs of dialysis represent a large financial burden on the U.S. healthcare system [35]. Both decreased glomerular filtration rate (GFR) and albuminuria have been shown to be independent risk factors for cardiovascular events such as myocardial infarction and stroke in diabetics [36].

\section{Neuropathy}

Autonomic and somatic neuropathies affect up to $50 \%$ of diabetics. The symptoms of somatic neuropathy are varied in degree of pain and location and can have late complications such as foot lesions and deformities leading to amputation [37]. Hyperglycemia leading to free radical superoxide mutation increases sorbitol and fructose formation through the polyol pathway, increases the concentration of AGE's, activates protein kinase $\mathrm{C}$, and increases the hexosamine pathway flux. All of these mechanisms lead to impaired neural function and apoptosis of Schwann cells [38].

\section{Erectile dysfunction}

Erectile dysfunction (ED) or impotence is a sexual dysfunction characterized by the regular or repeated inability to obtain or maintain an erection of the penis during sexual activity. Globally, sexual disorders have a prevalence of $18-42 \%$ [39]. Erectile dysfunction is ranked as the third most important complication of diabetes mellitus and has a prevalence of $50 \%$ in diabetic patients $[39,40]$. In diabetic men, semen analyses reveal a decrease in sperm motility and density and also abnormal morphology. Even when diabetic men present with normal semen studies, there is a higher level of damage to both nuclear and mitochondrial DNA when compared to healthy controls [41].

The pathophysiology of ED in diabetes is not well understood but associated neurological, vascular, and endothelial dysfunctions are major contributors [40]. During normal sexual activity nitric oxide (NO) is released from either the penile nerve ending or the vascular endothelium, triggering relaxation of both cavernosal arteries and surrounding smooth muscle. This promotes an increase in penile blood flow which eventually leads to an erection. Diabetic patients have impaired NO production and a significant increase in NO synthase (NOS) binding sites leading to a decrease in endotheliumdependent smooth muscle relaxation [42-44]. In addition, AGE's quench NO activity by increasing the expression of mediators of vascular damage such as vascular endothelial growth factor (VEGF) and endothelin-1 (ET-1). The end result is vasoconstriction and vascular proliferation leading to fibrosis [44].

Since there is no curative treatment for ED, the first step in ED management involves lifestyle modification, avoidance of hyperglycemia, and treatment of hypogonadism. Phosphodiesterase type 5 inhibitors such as sildenafil are the first-line treatment option. Second-line therapy involves intracavernous administration of vasoactive drugs such as alprostadil, papaverine, amd phentolamine. Penile prosthesis is considered in refractory cases and has excellent results in the appropriate patient population [40]. Current research is aimed at transferring a gene coding for a calcium-sensitive potassium channel (hMaxi-K) via penile injection [45].

\section{Complications of pregnancy}

Gestational diabetes mellitus (GDM) is defined as glucose intolerance of variable degree with onset during pregnancy and accounts for $90 \%$ of cases of diabetes in pregnancy. Preexisting type 2 diabetes accounts for $8 \%$ of cases. However, that proportion is rising with the rapidly rising prevalence of diabetes mellitus [46]. During pregnancy, hormones and other factors are thought to bind to insulin receptors and interfere with its function. Although the etiology is not yet clear, this interference likely occurs at the level of the cell signaling pathway of the insulin receptor itself [47]. The early identification and diagnosis of gestational diabetes is the cornerstone to avoiding significant complications for mother and child.

Risks to the mother include diabetic retinopathy, hypertension, preeclampsia, eclampsia, HELLP syndrome, placental abruption, and stroke. It has been shown that $50 \%$ of pregnant women with preexisting retinopathy experienced deterioration during pregnancy. Most of these patients had partial regression following delivery and some even returned to their pre-pregnancy baseline. Rapid induction of glycemic control early in pregnancy stalls retinal vascular proliferation [48]. During pregnancy, renal blood flow and glomerular filtration rate are significantly increased. The kidneys are particularly predisposed to damage in this state. Pregnant women should be screened with an oral glucose tolerance test between 24-28 weeks of gestational age to avoid this complication. If the diagnosis of gestational diabetes is made, a follow up screening should be performed 6 weeks after delivery [49].

Infants of mothers with diabetes mellitus experience double the risk of serious injury at birth, triple the likelihood of cesarean delivery, and quadruple the incidence of newborn intensive care unit admission. The risks of maternal diabetes to the developing fetus include miscarriage, growth restriction, macrosomia, polyhydramnios, perinatal mortality, and mild neurological and cognitive deficits. Neural tube defects are 20 times more frequent in diabetic pregnancies. Gestational diabetes mellitus and impaired glucose tolerance during pregnancy are associated with persistent metabolic dysfunction at 3 years after delivery, separate from other clinical risk factors [50].

\section{Metabolic syndrome}

The MetS criteria (abnormal waist circumference, high blood pressure, high fasting plasma glucose and insulin levels, homeostatic model assessment of insulin resistance, and increased fasting plasma lipids) are a cluster of related abnormalities designated as Syndrome X $[51,52]$. The prevalence of metabolic syndrome in the general population is $17-25 \%$ and predisposes individuals to type 2 diabetes, cardiovascular disease, essential hypertension, certain forms of cancer, polycystic ovarian syndrome, non-alcoholic fatty liver disease, and sleep apnea $[53,54]$. The combination of insulin resistance and compensatory hyperinsulinemia increases the likelihood that an individual with be hypertensive and have high plasma triglyceride and low HDL concentrations. Hyperinsulinemia increases plasminogen activator inhibitor-1 (PAI-1) concentrations, which has been shown to be associated with cardiovascular disease [52]. The sympathetic nervous system and renin-aldosterone system each respond to high 
plasma insulin levels by vasoconstricting and retaining sodium, resulting in hypertension.

Diabetes is a complicated disease process which has diverse and significant effects on the human body. Unfortunately, medicine has become a significant contributor to U.S. budget expenditures without much improvement in outcomes as compared to other countries. With a steadily increasing prevalence and numerous, costly implications; diabetes may be the reason for this. U.S. healthcare policy should focus its efforts on the prevention of obesity and subsequently decrease the immense burden imposed by diabetes.

\section{References}

1. American Diabetes Association (2014) Standards of Medical Care in Diabetes-2014. Diabetes Care 14-80.

2. American Diabetes Association (2013) Economic costs of diabetes in the U.S. in 2012. Diabetes Care 36: 1033-1046.

3. Boyle JP, Thompson TJ, Gregg EW, Barker LE, Williamson DF (2010) Projection of the year 2050 burden of diabetes in the US adult population: dynamic modeling of incidence, mortality, and prediabetes prevalence. Popul Health Metr 8: 29.

4. Mokdad AH, Ford ES, Bowman BA, Dietz WH, Vinicor F, et al. (2003) Prevalence of obesity, diabetes, and obesity-related health risk factors, 2001. JAMA 289: 76-79.

5. Nathan DM, Meigs J, Singer DE (1997) The epidemiology of cardiovascular disease in type 2 diabetes mellitus: how sweet it is ... or is it? Lancet 350 Suppl 1: SI4-9.

6. Center for Disease Control and Prevention, National diabetes fact sheet national estimates and general information on diabetes and prediabetes in the United States, Atlanta, GA, USA, 2011.

7. Haffner SM, Lehto S, Rönnemaa T, Pyörälä K, Laakso M (1998) Mortality from coronary heart disease in subjects with type 2 diabetes and in nondiabetic subjects with and without prior myocardial infarction. N Engl J Med 339: 229-234.

8. National Cholesterol Education Program (2002) Third Report of the National Cholesterol Education Program Expert Panel on Detection, Evaluation, and Treatment of High Blood Cholesterol in Adults Final Report. Circulation 3143-3421.

9. Gao Y, Lu B, Sun ML, Hou ZH, Yu FF, et al. (2011) Comparison of atherosclerotic plaque by computed tomography angiography in patients with and without diabetes mellitus and with known or suspected coronary artery disease. Am J Cardiol 108: 809-813.

10. Griendling KK (2004) Novel NAD(P)H oxidases in the cardiovascular system. Heart 90: 491-493.

11. De Vriese AS, Verbeuren TJ, Van de Voorde J, Lameire NH, Vanhoutte PM (2000) Endothelial dysfunction in diabetes. Br J Pharmacol 130: 963-974.

12. Luft FC (2002) Proinflammatory effects of angiotensin II and endothelin: targets for progression of cardiovascular and renal diseases. Curr Opin Nephrol Hypertens 11: 59-66.

13. Golovchenko I, Goalstone ML, Watson P, Brownlee M, Draznin B (2000) Hyperinsulinemia Enhances Transcriptional Activity of Nuclear Factor-B Induced by Angiotensin II, Hyperglycemia, and Advanced Glycosolation End Products in Vascular Smooth Muscle Cells. Circulation Research 746-752.

14. O'Driscoll G, Green D, Rankin J, Stanton K, Taylor R (2014) Improvement in Endothelial Function by Angiotensin Converting Enzyme Inhibition in Insulin-dependent Diabetes Mellitus. The Journal of Clinical Investigation 678-684.

15. Stratmann B, Tschoepe D (2009) Atherogenesis and atherothrombosis-focus on diabetes mellitus. Best Pract Res Clin Endocrinol Metab 23: 291-303.

16. Breitenstein A, Tanner FC, Lüscher TF (2010) Tissue factor and cardiovascular disease: quo vadis? Circ J 74: 3-12.
17. Li D, Chen K, Sinha N, Zhang X, Wang Y, et al. (2005) The effects of PPAR-gamma ligand pioglitazone on platelet aggregation and arterial thrombus formation. Cardiovasc Res 65: 907-912.

18. Boden G, Vaidyula VR, Homko C, Cheung P, Rao AK (2007) Circulating Tissue Factor Procoagulant Activity and Thrombin Generation in Patients with Type 2: Diabetes: Effects of Insulin and Glucose. The Journal of Clinical Endocrinology and Metabolism.

19. Wang J, Wu J, Zhang S, Zhang L, Wang C, et al. (2014) Elevated fasting glucose as a potential predictor for asymptomatic cerebral artery stenosis: A cross-sectional study in Chinese adults. Atherosclerosis 237: 661-665.

20. Rawlings AM, Sharrett AR, Schneider AL, Coresh J, Albert M, et al. (2014) Diabetes in midlife and cognitive change over 20 years: a cohort study. Ann Intern Med 161: 785-793.

21. Chahal H, Bluemke DA, Wu CO, McClelland R, Liu K, et al. (2015) Heart failure risk prediction in the Multi-Ethnic Study of Atherosclerosis. Heart 101: 58-64.

22. Sowers JR, Epstein M (1995) Diabetes mellitus and associated hypertension, vascular disease, and nephropathy. An update. Hypertension 26: 869-879.

23. El-Atat F, McFarlane SI, Sowers JR (2004) Diabetes, hypertension, and cardiovascular derangements: pathophysiology and management. Curr Hypertens Rep 6: 215-223.

24. Sowers JR (2004) Treatment of hypertension in patients with diabetes. Arch Intern Med 164: 1850-1857.

25. Randeree HA, Omar MA, Motala AA, Seedat MA (1992) Effect of insulin therapy on blood pressure in NIDDM patients with secondary failure. Diabetes Care 15: 1258-1263.

26. Nosadini R, Sambataro M, Thomaseth K, Pacini G, Cipollina MR, et al. (1993) Role of hyperglycemia and insulin resistance in determining sodium retention in non-insulin-dependent diabetes. Kidney Int 44: 139-146.

27. Cruickshank K, Riste L, Anderson SG, Wright JS, Dunn G, et al. (2002) Aortic pulse-wave velocity and its relationship to mortality in diabetes and glucose intolerance: an integrated index of vascular function? Circulation 106: 2085-2090.

28. Mogensen CE, Hansen KW, Pedersen MM, Christensen CK (1991) Renal factors influencing blood pressure threshold and choice of treatment for hypertension in IDDM. Diabetes Care 14 Suppl 4: 13-26.

29. McFarlane SI, Banerji M, Sowers JR (2001) Insulin resistance and cardiovascular disease. J Clin Endocrinol Metab 86: 713-718.

30. UK Prospective Diabetes Study Group (1998) Tight blood pressure control and risk of macrovascular and microvascular complications in type 2 diabetes: UKPDS 38. BMJ 703-713.

31. Antonetti DA, Barber AJ, Bronson SK, Freeman WM, Gardner TW, et al. (2006) Diabetic retinopathy: seeing beyond glucose-induced microvascular disease. Diabetes 55: 2401-2411.

32. Gardner TW, Antonetti DA, Barber AJ, LaNoue KF, Levison SW (2002) Diabetic retinopathy: more than meets the eye. Surv Ophthalmol 47 Suppl 2: S253-262.

33. Huang H, He J, Johnson D, Wei Y, Liu Y, et al. (2015) Deletion of Placental Growth Factor Prevents Diabetic Retinopathy and Is Associated With Akt Activation and HIF1 $\hat{I} \pm-$ VEGF Pathway Inhibition. Diabetes 64: 200-212.

34. Ioannidis I (2014) Diabetes treatment in patients with renal disease: Is the landscape clear enough? World J Diabetes 5: 651-658.

35. de Boer IH, Rue TC, Hall YN, Heagerty PJ, Weiss NS, et al. (2011) Temporal trends in the prevalence of diabetic kidney disease in the United States. JAMA 305: 2532-2539.

36. Ninomiya T, Perkovic V, de Galan BE, Zoungas S, Pillai A, et al. (2009) Albuminuria and kidney function independently predict cardiovascular and renal outcomes in diabetes. J Am Soc Nephrol 20: 1813-1821.

37. Boulton AJ, Malik RA, Arezzo JC, Sosenko JM (2004) Diabetic somatic neuropathies. Diabetes Care 27: 1458-1486.

38. Feldman EL (2003) Oxidative stress and diabetic neuropathy: a new understanding of an old problem. J Clin Invest 111: 431-433. 
Citation: Giquel J, Nieto M, Matadial C, Palermo C (2014) Cardiovascular Manifestations of Hyperglycemia: A Review Article. J Gen Practice 2: 191. doi:10.4172/2329-9126.1000191

Page 5 of 5

39. Arrellano-Valdez F, Urrutia-Osorio M, Arroyo C, Soto-Vega E1 (2014) A comprehensive review of urologic complications in patients with diabetes. Springerplus 3: 549.

40. Hatzimouratidis K, Hatzichristou D (2014) How to treat erectile dysfunction in men with diabetes: from pathophysiology to treatment Curr Diab Rep 14: 545.

41. Agbaje IM, Rogers DA, McVicar CM, McClure N, Atkinson AB, et al (2007) Insulin dependant diabetes mellitus: implications for male reproductive function. Hum Reprod 22: 1871-1877.

42. Rehman K, Beshay E, Carrier S (2001) Diabetes and male sexual function. J Sex Reprod Med 1: 29-33.

43. De Young L, Yu D, Bateman RM, Brock GB (2004) Oxidative stress and antioxidant therapy: their impact in diabetes-associated erectile dysfunction. J Androl 25: 830-836.

44. Morano S (2003) Pathophysiology of diabetic sexual dysfunction. J Endocrinol Invest 26: 65-69.

45. Christ GJ, Anderson KE, Williams K, Zhao W, D'Agostino R, et al. (2009) Smooth Muscle-Specific Gene Transfer with the Human Maxi-K Channel Improves Erectile Function and Enhances Sexual Behavior in Artherosclerotic Cynomolus Monkeys. European Urology 891-1104.

46. Baptiste-Roberts K, Barone BB, Gary TL, Golden SH, Wilson LM, et al. (2009) Risk factors for type 2 diabetes among women with gestational diabetes: a systematic review. Am J Med 122: 207-214.
47. Carr DB, Gabbe S (1998) Gestational Diabetes: Detection, Management, and Implications. Clin Diabetes.

48. Hopp H, Vollert W, Ebert A, Weitzel H, Glöckner E, et al. (1995) Diabetic retinopathy and nephropathy--complications in pregnancy and labor. Geburtshilfe Frauenheilkd 55: 275-279.

49. Ross G (2006) Gestational diabetes. Aust Fam Physician 35: 392-396.

50. Stuebe AM, Mantzoros C, Kleinman K, Gillman MW, Rifas-Shiman S, et al. (2011) Gestational glucose tolerance and maternal metabolic profile at 3 years postpartum. Obstet Gynecol 118: 1065-1073.

51. Elder SJ, Lichtenstein AH, Pittas AG, Roberts SB, Fuss PJ, Greenberg, et al. (2009) Genetic and environmental influences on factors associated with cardiovascular disease and the metabolic syndrome. Journal of Lipid Research 1917-1926.

52. Reaven GM (1988) Banting lecture 1988. Role of insulin resistance in human disease. Diabetes 37: 1595-1607.

53. Sydow K, Mondon CE, Cooke JP (2005) Insulin resistance: potential role of the endogenous nitric oxide synthase inhibitor ADMA. Vasc Med 10 Suppl 1: S35-43.

54. AlSaraj F, McDermott JH, Cawood T, McAteer S, Ali M, et al. (2009) Prevalence of the metabolic syndrome in patients with diabetes mellitus. Ir J Med Sci 178: 309-313. 